\title{
Globalization as a socio-environmental equilibrium: applying Luhmann's theory to Integrated Reporting
}

\author{
Evgnii Razumov ${ }^{1}$ \\ ${ }^{1}$ Department of Statistics, Accounting and Audit, Faculty of Economics, Saint-Petersburg State \\ University, Chaikovskogo street 62, Saint-Petersburg, Russia
}

\begin{abstract}
International accounting standards systems are able to define borders by producing reference codes for institutional, informational and cultural codes. Such ways of influence are similar to globalization in other societal spaces: for example internalization of trade systems has been produced by creating institutes and organizations as well as miscellaneous standards. These tendencies have been highlighted by Niklas Luhmann through differentiation of borders determinants of a system. And this operational determination of globalization as continual creation of the world system is to be highly appreciated for comprehensive analysis of the last developments in accounting and reporting field influenced by environmental issues. In this paper three-tier classification of globalization in terms of system definition proposed as development of Niklas Luhmann ideas. Through analysis of the mean shifts in reporting as social memory phenomenon and communication process accounting problems reformulated as world system 's issues and demonstrated existence of globalization as operational phenomenon for accountancy and social responsibility systems. Concepts of the social systems theory have been visualized and interpreted to determine possible ways of equilibrium states for human systems and environment. As a result main ways for integrated reporting application and its future development formulated.
\end{abstract}

\section{Introduction}

Globalization obviously does not answer equilibrium question by itself. So we propose socio-envirionmental equilibrium as complex problem that could be addressed through syntheses of developments of different disciplines and institutions. In present article a review of particular aspects of Niklas Luhmann's theory and its interpretations are represented in context of globalization problem. Other literature reviewed in this sense to provide evidence for interdisciplinary influences of sociology, economics, accounting, ecology and law and define ways for such developments in future. We use comparative analysis and propose world system types classification as well as structure contingencies to model sociological application to actual global problems and to demonstrate integrated reporting as one of key potential mean of establishing global equilibrium of the world system. 


\section{Globalization and world society}

\subsection{Views on world society}

According to Modern Systems Theory global society is seen as world society for the entirety of meaning as well as for empirical evidence of global communication availability[1]. Niklas Luhmann works established basis for central role of communication in societal systems as well as linked meaning, selection and decision dynamics in the systems. So his theoretical developments are important in describing globalization process.

He writes that in the simple case one can determine borders alongside neighbouring systems borders, while such a way is becoming more and more illusory. Thus the more realistic approach for Niklas Luhmann was to find some internal ways for determining borders by autopoietic self-referent operationally closed but openly communicating systems[2]. So operational determination of globalization as creating of world systems is to be highly appreciated for comprehensive analysis of the last tendencies in highly complex and important field as accounting and financial/non-financial reporting.

In the conditions of complexity gradients in international relations it's necessary to establish borders for particular spheres so that trade and economic fields can get more freedom to form complex and effective systems. And in this circumstances reporting and accounting get new possibilities for restructuring and evolution because of observation role and by creation of expectations. Observers of systems (in this case systems of organisation, communities, society and environment) may see more continuous relations and processes then even the systems puts in internal meanings[2]. One of the reasons for this is elimination of dividing borders when each system can determine it's one borders. Such a complexity is a reasonable basis for shift from particular reporting standards to many parallel reporting systems. Thus functioning of different reporting systems (Integrated Reporting, Global Reporting Initiative and other environmental and social reporting) is wholly norm to globalization phenomenon.

Though Niklas Luhmann writes about complexity determination through social systems placing in the field of ecology problems (that are in itself the most complex problems that globalization faces), it can be argued as well that the same kind of problems lies inside social systems because globalization produced views such as one of the end of history that puts different human groups and civilizational subsystems in the position of external environment for the globalized part. Niklas Luhmann notes in this respect that ecological problems could not be resolved without distinction of system and complexity because environment in itself not regulated by complexity[2] (and double contingency). Indeed this notion can allow to separate the third option for list of globalization views:

1. classical view - globalization as forming of the only world trade-productionlife system where borders are internalized and effectively regulated;

2. world-system conception - globalization as one aspect of many intertwined systems with manifold borders definition;

3. many societies and nature representations through systems as well as complexities.

Distinction between the classical view and world-system conception is established by of Luhmanns's position when he concludes that presentation of system as elements and relations between them is obsolete and communication is by itself part of restriction as communication (restriction of others as well as of self-restriction), only by active selection could be determined new connections, but not by elements or structure itself[2]. And this notion of selection is essentially exemplified by competitive selection in market economy systems. 
Classical view is itself consistent with traditional societies when key principles were stratification and hierarchy[3]. Meanwhile Niklas Luhmann's article apprises other question: "Globalization or world society". While he appeals for culture codes as memory function of a system the answer it seems that in order to describe and use the term of "world society' sociology by itself should be capable for it[3]. And because of another re-entry the question can not be answered. By proposing that the world-system could be observed even only in dynamic unsustainable equilibrium we could try to use integrated reporting as one of effective subsystems. The potential for such an ambisonics role follows from studies showing significance of human and other forms of social capital as well as of natural capital. For example, a recent study of U.S. income distribution demonstrated prevalence of human capital role over financial capital one for private business profit generation[4]. Thus integrated reporting comprising arguably the most important capitals as well as shifting focus onto non-financial aspects is to be seen as a primary reporting system for globalize world societies.

Then it could be demonstrated that the difference between 2 and 3 options is consistent with the difference between weak and strong sustainability because of value-creation approaches and capital substitution concepts. While integrated reporting is not considered to have generally accepted purposes and theoretical basis and it could be researched rather as 'idea journey' [5] so it could be compatible with any option. On the other hand traditional (pre-financial) reporting systems could be consistent generally with 1 and 2 options. Consequentially usage of different reporting frameworks in globalized world means misunderstanding and divergence in thinking that are to be overcome by development of globalized (or indeed inter-societal) social systems. Indeed non-financial reporting including integrated one could play different roles for different societies and organizations dependent on diverse factors including institutional environment and media type used[6]. But these factors are in essence analyzed by application of social systems theory to reporting as a communication process. Indeed it seems that many authors have argued for more narrative context of integrated reporting that creates meaningful dialogue, facilitates socializing forms of accountability[7]. Therefore there is potential for expansion if integrated reporting within globalization of 3 type as creating references and formalizing contingencies. Evidence for this has been found in research of financial reporting complexity that is described as increasing one, while other (non-mandatory) disclosures and accounting expertise are creating basis for 'optimal information environment' [8]. Besides this integrated reporting is itself criticized for focusing on value for investors but not society or nature[9] so the potential for existence of different reporting frameworks as well as of different kinds of integrated reporting is to be persistent. This conclusion could be broadened to argue that globalization process itself can simultaneously contain all the considered above options (while integrated reporting and other forms of reporting just fallow such a multiplicity). And then social systems condense into forms consistent with one option or another particularly through such institutions as integrated reporting. 3 option in this sense is the more universal one and allows to use any reporting mechanism if it arguably creates some schematization and considered by public as communication process in first place. Yet in practice loss of meaning (financial as well as social, legal, environmental etc.) should take place that could be discovered and minimized as it will be argued therein under. 


\subsection{Diversity of the dimensions}

Phenomenon of globalization should be considered in context of objective dimension when development of internal self-reference of the dimension results in removal of external horizons and depletion of all elements[2]. But this perspective dates back to Modern age while contemporary globalization of postmodernity expressed in the completion of the schematization. Considering the new time dimension globalization is linked with the end of history, while the historical schematization then is part of the dimension but only if it adequate to requirements. Social dimension on the other hand nowadays is highlighted by expansion of social networks, messengers that textualize meaning through exclusive inclusion thus the dimension gets more and more autonomy. Therefore we can conclude that globalization phenomena develop themselves at the limits of disunity of meaning dimensions. According to Niklas Luhmann the disunity contains something positive: growth of potential to recombine, growth of historical consciousness, widening of reflected social sensitivity, as well as negative: growth of complexity, difficulty to mediate between social dimensions, contextual specificity, erosion of traditional cultures[2]. As a result Luhmann notes lack of ratio in global system, while development may go by the way of complex integrating dimension of consciousness.

One of such ways could become integrated reporting itself created as a unifying framework among divergent social and environmental reporting practices. But it's not expected to play dominant role because GRI-type reports contain more information and financial reports are better structured so that it's rationale to expand dimensions of organizational activities through 'interplay of reporting frameworks'[10]. So to create effective reporting communication systems the dimensions are to be aligned and codified not just placed into informational field because by itself reports does not create communications. Yet even high-level horizontal alignment between IFRS and GAAP regulatory bodies is considered to be slow and ineffective[11]. Thus the alignment should may be start from below to be consistent with the third globalization option.

\section{Reporting communication systems}

\subsection{Reporting as communication}

In the core of globalization nowadays we should place communication and information processes and this tendency is itself provides an evidence for increasing complexity of societal and economic systems, that is being constructed internally by models, risk describing and enterprise resource planning means and externally through reporting communications. Such border bodies allow systems to be undefinable for each other while communication systems are needed to regulate the situation[2]. Thus international reporting standards as well as trade standards are to be included into communications systems cluster and one of the key goals for them is to transform internal uncertainty into international stakeholders interpretation as well as to find equilibrium with the wider environment.

While communication cannot be observed in itself, it can be reconstructed through actions and informational tails. Therefore there are wide availabilities for miscellaneous reporting structures and means if they are to absorb divergent uncertainties through common horizons.

Through modelling different complexities are reduced to one another[2], for example environmental complexity is reduced through integrated reporting (IR) perspective. Thus modelling of differences between different types of capital in integrated reporting means many reductions of complexities. While financial reporting is a closed communication system in itself alongside with budgeting and planning system it's necessary to reduce 
complexities of such systems to get an integrated view. So the IR would always contain some reduced complexity. Thus IR could either use some reporting system as a basis to create integrated accounting as independent system based on wider complexity or try to adopt present accounting and information systems.

Since integrative role of meaning is central for Luhmann's social theory[12] integrated thinking may be seen as a particular form of such a meaning setting. Indeed, conditioned communication process is creation of social systems themselves and this communications can be seen as filling of a system by meaning[2]. Then financial reporting as well as integrated reporting (IR) take a central role in creating of organizational systems by communicating information through different forms to stakeholders. But on the other hand IR as a framework is a social structure that can be placed both in economic and law fields because of contemporary discussion leading to exclusivity of price language (associated with economics) and norm language (associated with law)[13].

It should be said that term 'integration' in itself entails conflicting essence that is not expressed openly in developed IR standards. According to Niklas Luhmann integration is 'limitation of the degrees of freedom that components have' and it's achievement means reduction of options and qualities for a system. And the reductionism is similar to results of conflict[14]. While global ecological crisis is the obvious side of such a conflict reductionism the other may be divergent interests and opinions of stakeholders and other participants in activities of organisations. Thus we can conclude that IR by itself is not set to construct more harmonized autopoietic systems while in order to resolve issues of conflicts one should revoke such Luhmann's suggestions as loose coupling and conceiving of law as an institution[14], that could be already seen in ways IR is issued and regulated contrasting with IFRS or U.S. GAAP regulation. So we should expect further development of distinctive ways that IR system is organized, for example, creation of open online datasets or appearing of independent verification initiative groups. In empirical studies it now has been shown that both stimulus and codes are associated with different reporting frameworks[15] while mandatory IR is more effective on financial results than voluntary one[16]. Thus different social and environmental approaches are combined and proposedly should be regulated. But basis for such regulatory decisions should promote meaning creation and widen international dialogue and can be structured as equilibrium model proposed below.

\subsection{Equilibrium reporting}

Earlier has been suggested that Luhmann's theory should be expanded in the field of integrated reporting[17]. So concluding this article we will combine explained above views on society with some elements of Luhmann's theory that have key relevance for integrated or other globalized reporting systems using historical evolutionary gradation of them. So attribution of means in 'res corporales/res incorporales' has been changed by subjectivity and idealism theories, while Niklas Luhmann used autopoietic individualisation as explanatory basis. Placing these elements alongside each other we propose equilibrium model of triple contingency: 

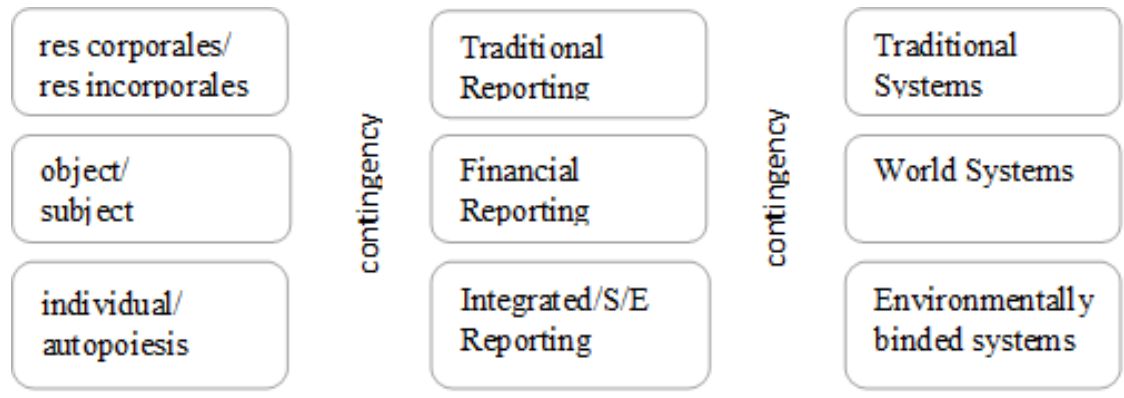

Fig. 1. Equilibrium model of triple contingency.

Equilibrium could be reached by multiple levels of contingency, each of which is itself two-dimensional: first of all it is contingency between systems and structures of different levels and secondly it is contingency of choosing and observing different frameworks, words, codes, norms. But at face of globalization as global platform for crisis-creation equilibrium could be seen primary through combination of autopoietic individuals, some form of integrated/social/environmental reporting and proposed view of double contingency with environment. At the same time other forms of combinations are possible with the third type of globalization but in this case loss of meaning should be taken into account.

\section{Conclusion}

Effective ways for IR development, adaptation and convergence today are dependent on social theory and studies of Niklas Luhmann in this relation are very significant. First of all question about world systems and globalization should be answered because IR as well as other reporting frameworks are positioned as global standards. We proposed 3 types of globalization in accordance with studies of Niklas Luhmann and have examined their compatibility with types of reporting. It has been argued that the third type of many societies and nature representations enables simultaneous inclusion of different reporting frameworks into social communication process for effective meaning creation.

Then we reviewed IR regulation and usage capabilities for creation of communication systems and assessed them as positive in general. Finally equilibrium model proposed for further studies of reporting as a communication system to prevent unpredictable loss of meaning and to construct effective reporting dialogue.

\section{References}

1. M. Albert, L. Hilkermeier, Organizations in/and world society: a theoretical prolegomenon. Observing International Relations. Niklas Luhmann and World Politics, 177-195 (2004).

2. Luhmann N, Social'nye sistemy: ocherk obshey teorii. (Nauka, Sankt-Peterburg, 2007).

3. N. Luhmann, Globalization or world society: how to conceive of modern society? International review of sociology, 7, 1 (1997).

4. M. Smith, D. Yagan, O. Zidar, E. Zwick, Capitalists in the Twenty-First Century. The Quarterly Journal of Economics, 134, 1675-1745 (2019).

5. L. Rinaldi, J. Unerman, C. De Villiers, Evaluating the integrated reporting journey: insights, gaps and agendas for future research. Accounting, Auditing \& Accountability Journal, 31, 1294-1318 (2018). 
6. D. Reimsbach, R. Hahn, A. Gürtürk, Integrated reporting and assurance of sustainability information: An experimental study on professional investors' information processing. European Accounting Review, 27, 559-581 (2018).

7. A. Lai, G. Melloni, R. Stacchezzini, Integrated reporting and narrative accountability: The role of preparers. Accounting, Auditing \& Accountability Journal, 31, 1381-1405 (2018).

8. R. Chychyla, A.J. Leone, M. Minutti-Meza, Complexity of financial reporting standards and accounting expertise. Journal of Accounting and Economics, 67, 226253 (2019).

9. W. Stubbs W., C. Higgins, Stakeholders' perspectives on the role of regulatory reform in integrated reporting. Journal of Business Ethics, 147, 489-508 (2018).

10. C. De Villiers, U. Sharma, A critical reflection on the future of financial, intellectual capital, sustainability and integrated reporting. Critical Perspectives on Accounting (2017).

11. S. Lin et al., Relative effects of IFRS adoption and IFRS convergence on financial statement comparability. Contemporary Accounting Research, 36, 588-628 (2019).

12. N. Luhmann, Theory of society. (Stanford University Press, USA, 2012)

13. N. Luhmann, Ecological communication. (University of Chicago Press, USA, 1989)

14. N. Luhmann, Introduction to systems theory. (Cambridge Malden, MA: Polity, UK, 2013)

15. M. M. Wachira, T. Berndt, C. M. Romero, The adoption of international sustainability and integrated reporting guidelines within a mandatory reporting framework: lessons from South Africa. Social Responsibility Journal (2019).

16. A. Pavlopoulos, C. Magnis, G.E.Iatridis, Integrated reporting: An accounting disclosure tool for high quality financial reporting. Research in International Business and Finance, 49, 13-40 (2019).

17. D. Alexander, V. Blum, Ecological economics: A Luhmannian analysis of integrated reporting. Ecological Economics, 129, 241-251 (2016). 